\title{
AVALIAÇÃO DA PROTEÍNA HBZ NO DESENVOLVIMENTO DA LEUCEMIA/LINFOMA DE CÉLULAS T DO ADULTO: UMA REVISÃO SISTEMÁTICA
}

\author{
EVALUATION OF HBZ PROTEIN FUNCTION IN THE DEVELOPMENT \\ OF ADULT T-CELL LEUKEMIA/LYMPHOMA: A SYSTEMATIC REVIEW
}

\author{
Caroline Rocha, Fernanda Barreto
}

Escola Bahiana de Medicina e Saúde Pública

\section{Abstract}

The HTLV-1 bzip factor protein (HBZ) is produced by HTLV-1 infected cells and its expression is consistently found in cells of Adult T-Cell Leukemia/Lymphoma (ATLL) individuals. ATLL is a serious disease and, although some treatments have satisfactory outcomes, there is still no known cure. HBZ was described previously as one of the viral proteins that induce proliferation and immortalization in infected cells. As HBZ is always expressed in ATLL cells, it is important to discuss the $H B Z$ mechanisms that contribute to the development of ATLL to assist further studies about treatment and prevention of HTLV-1 diseases. Therefore, the main objective of this study is to investigate the roles of $\mathrm{HBZ}$ on the development of ATLL. This systematic review was made with articles found in PubMed database. 61 articles were found, 20 were included and their data collected. From the data obtained, it was possible to conclude that HBZ protein is important on the development of ATLL because it contributes to proliferation, immortalization and survival of ATLL cells. However, it is still not clear if $\mathrm{HBZ}$ participates on the initial mechanism of ATLL development.

Keywords: HBZ; HTLV-1; ATLL.

\section{Resumo}

A proteína HTLV-1 bzip factor (HBZ) é produzida pelas células infectadas pelo HTLV-1 e sua expressão se dá de forma constante em células de indivíduos com Leucemia/Linfoma de Células $T$ do Adulto (ATLL). Essa patologia é grave e, apesar de existir tratamentos que reduzam os sintomas e aumentem a sobrevida do paciente, ainda não existe cura conhecida para a infecção pelo HTLV-1. A HBZ foi descrita como uma das principais proteínas virais que induzem proliferação e imortalização celular da célula infectada pelo HTLV-1. Como a HBZ é sempre expressa em células de pacientes com ATLL, é importante discutir os mecanismos de atuação dessa proteína para auxiliar estudos futuros sobre tratamento e prevenção de doenças provocadas pelo HTLV-1. Portanto, esse trabalho possui como objetivo principal investigar as vias de atuação dessa proteína no desenvolvimento da ATLL. Essa revisão sistemática foi realizada a partir de artigos encontrados na plataforma de busca do PubMed. Foram encontrados 61 artigos, destes 20 foram incluídos e seus dados foram coletados. A partir dos dados obtidos, é possível concluir que proteína HBZ é importante no desenvolvimento de ATLL ao contribuir na proliferação, imortalização e sobrevivência das células infectadas. Porém ainda não está claro se a HBZ participa do mecanismo inicial de desenvolvimento da ATLL.

Palavras chave: HBZ; HTLV-1; ATLL. 
Introdução

O vírus linfotrópico de células T humanas do tipo 1 (HTLV-1) é um retrovírus caracterizado como o tipo exclusivo causador de uma leucemia chamada Leucemia/Linfoma de Células $T$ do Adulto (ATLL) ${ }^{1}$. Em 2012, foi estimado que cerca de 5-10 milhões de pessoas no mundo estavam infectadas com HTLV-1, enquanto no Brasil o número estimado de infectados pelo HTLV-1 é de 2,5 milhões ${ }^{2,3}$.

$\mathrm{O}$ indivíduo infectado pelo HTLV-1 pode permanecer assintomático ao longo da vida e não saber que é portador, porém alguns indivíduos podem desenvolver doenças inflamatórias como tireoidite, dermatite infecciosa associada ao HTLV-1, artropatia, uveite associada ao HTLV-1 e poliomiosite ${ }^{4,5}$. Além disso, aproximadamente $5 \%$ dos pacientes desenvolvem alguma patologia grave como a Paraparesia Espástica Tropical/Mielopatia associada ao HTLV-1 (HAM/TSP) e a ATLL ${ }^{4,5}$.

A ATLL é um câncer associado a infecção pelo HTLV-1 em linfócitos $T$ humanos, principalmente do tipo $\mathrm{T} \mathrm{CD}^{+}$, levando a transformação maligna dessas células e posterior proliferação monoclonal ${ }^{6}$. É uma doença sem cura conhecida e, em suas formas mais agressivas, o paciente pode chegar a apresentar linfoadenomegalia, infiltração pulmonar, hepatoesplenomegalia, além de lesões ósseas e lesões de pele ${ }^{7,8}$. O tratamento consiste principalmente em quimioterapia ${ }^{9}$. Contudo, a quimioterapia é um tratamento pouco efetivo e os pacientes em tratamento possuem uma sobrevida média de aproximadamente oito meses após o desenvolvimento da doença ${ }^{10,11}$.

$A$ administração de medicamentos antivirais como zidovudina (AZT) e interferon-alfa (IFN) associado com a quimioterapia tem apresentado bons resultados como uma forma de tratamento para ATLL, assim como o transplante alogênico de células-tronco hematopoéticas, porém o mecanismo pelo qual esses métodos auxiliam no tratamento da infecção ainda não está claro na literatura ${ }^{12,13}$.

O genoma do HTLV-1 é composto pelos genes gag, pol e env, flanqueados por duas repetições terminais longas, denominadas $L_{T R}{ }^{7}$. Próximo à extremidade 3' o HTLV-1 possui ainda uma região gênica que codifica as proteínas regulatórias p12, p8, p13, p30, Tax e Rex, oriundas de diferentes Open Reading Frames (ORFs) dessa região, denominada $\mathrm{pX}^{14}$. Em 2002, foi descrita uma nova proteína, também oriunda da região gênica $\mathrm{pX}$, chamada de HBZ ou "bzip factor"7.
Estudos indicam que a HBZ seria indutora de proliferação das células infectadas pelo vírus e inibidora da apoptose, colaborando assim na imortalização, manutenção e multiplicação das células de ATLL ${ }^{6}$. Apesar de Tax ser vista como o principal fator oncogênico das células infectadas, a sua expressão é consideravelmente reduzida, ao passo que a $\mathrm{HBZ}$ é expressa de maneira ampla e constante nas células de $\mathrm{ATLL}^{15}$. Por este motivo, a HBZ poderia ser um novo alvo de estudos para uma nova abordagem terapêutica da ATLL 9 .

Em 2015, estudos experimentais em murinos utilizando a proteína HBZ como alvo terapêutico já começaram a ser feitos ${ }^{16}$, porém os mecanismos que envolvem a $\mathrm{HBZ}$ no desenvolvimento de ATLL ainda não estão esclarecidos e a discussão dos estudos atuais sobre essa proteína são importantes para auxiliar estudos futuros sobre tratamento e prevenção de doenças provocadas pelo HTLV-1. Diante disso, a presente revisão objetivou investigar as vias de atuação da HBZ no desenvolvimento da ATLL, discutindo os efeitos dessa proteína em células $T$ humanas, assim como os fatores que podem influenciar a sua expressão, relação com a carga proviral e também a sua imunogenicidade.

\section{Metodologia}

Este trabalho consiste em uma revisão sistemática da literatura conduzida com auxílio do checklist do PRISMA (Principais Itens para Relatar Revisões sistemáticas e Meta-análises) ${ }^{17}$. exclusão

Estratégia de busca e critérios de inclusão e

A busca dos artigos foi realizada no banco de dados do PubMed/MEDLINE em agosto de 2017 e os descritores foram validados pelo Medical Subject Headings (MeSh). Os termos utilizados na pesquisa foram (HBZ or "bzip protein") AND (ATL OR ATLL OR "adult t-cell leukemia lymphoma" OR "adult t-cell leukemia" OR "adult t-cell lymphoma") AND ("Human Tlymphotropic virus type 1" OR HTLV-1). Na busca, foram utilizados os seguintes filtros: publicações dos últimos 5 anos e estudos apenas em inglês.

$\mathrm{Na}$ seleção dos artigos foram lidos o título e os resumos de todos os artigos encontrados a partir da pesquisa no banco de dados. Os critérios de inclusão foram: artigos originais que abordavam a HBZ e a ATLL em células humanas. Foram excluídos artigos sobre retrovírus correlacionados que não o HTLV-1, artigos que abordavam outra patologia associada ao HTLV-1 
que não a ATLL e duplicatas (Figura 1).

Figura 1 - Fluxograma sumarizando a busca sistemática e seleção dos artigos.
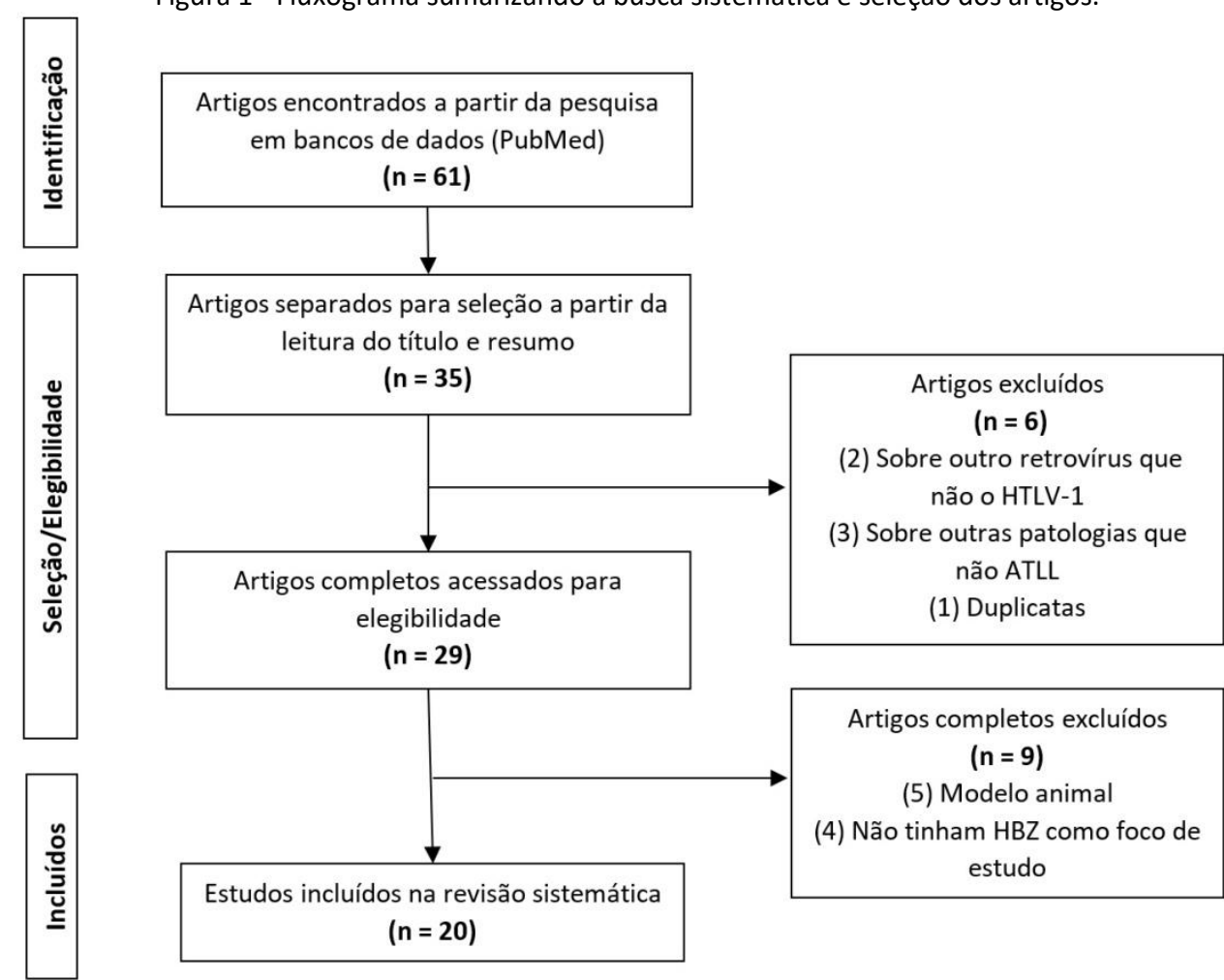

Artigos que abordam sobre HBZ e ATLL de forma simultânea com outras proteínas e/ou patologias associadas ao HTLV foram mantidos, porém apenas os dados relacionados à HBZ e ATLL foram coletados.

\section{Elegibilidade e coleta de dados}

Para determinar a elegibilidade, foi realizada a leitura do texto completo dos artigos selecionados. A partir dessa leitura, foram excluídos artigos que não tinham a HBZ como foco de estudo e também artigos que utilizaram modelo animal (Figura 1), já que o foco deste estudo é discutir os efeitos da HBZ em células humanas.

Dos artigos incluídos foram coletados os seguintes dados: autores, ano de publicação, método de mensuração/detecção da HBZ, linhagem celular utilizada e/ou população de estudo e principais resultados e conclusões.

\section{Resultados e discussão}

A partir da busca no PubMed, foram encontrados 61 artigos, onde 35 foram incluídos. Destes, 6 foram excluídos a partir da leitura do título e resumo e mais 9 foram excluídos após a leitura do texto completo. Dessa maneira, 20 artigos foram selecionados e todos os dados coletados estão sumarizados na Tabela Suplementar 1. Esses dados demonstram que a HBZ contribui para a imortalização celular e também influencia diversos processos associados a proliferação celular. Além disso, é uma proteína que possui uma baixa imunogenicidade, o que contribui para a evasão do sistema imune e a sobrevivência das células de ATLL.

\section{Alterações epigenéticas e instabilidade genética}

A HBZ é uma proteína viral que se localiza predominantemente no núcleo da célula da ATLL e possui um importante envolvimento em mudanças na expressão genica e alterações epigenéticas ${ }^{18,19,20,21,22}$. Foi constatado que a HBZ participa da diminuição da metilação da histona H3K9 ao prejudicar a ligação da proteína CENP-B ao DNA, o que contribui para o aumento da expressão gênica em células infectadas ${ }^{20}$. Além disso, a proteína HBZ leva a um aumento de miRNAs, principalmente miR17 e miR21, que atuam como reguladores da expressão genica ${ }^{22}$.

Os miRNAs miR17 e miR21 influenciam na expressão da proteína hSSB2, importante na reparação do DNA. Células expressando a HBZ 
apresentaram não só uma diminuição de hSSB2 como também um aumento de dano ao DNA ${ }^{22}$, contribuindo assim para a instabilidade genética das células de ATLL e o desenvolvimento de câncer.

\section{Imortalização celular}

A HBZ foi apontada como uma das principais proteínas no processo de imortalização celular na infecção pelo HTLV-1 e transformação das células $T$ em células leucêmicas ${ }^{9}$. Um dos principais mecanismos relacionados à carcinogênese em geral é o aumento de expressão da telomerase e a inativação de genes supressores de tumor. Em um estudo publicado em 2013, foi demonstrado que a HBZ, ao se associar com JunD e menin, formam um complexo que promove a expressão do gene da hTERT, componente da enzima telomerase, contribuindo assim para o aumento dos níveis dessa enzima na célula de $A_{T L L}{ }^{23}$. A ação da telomerase evita o encurtamento dos cromossomos e permite sucessivas divisões celulares sem dano ao DNA. Logo, o aumento dos níveis dessa proteína contribui para a imortalização dessas células ${ }^{24}$.

Já em 2016, outro estudo observou uma atividade reduzida do gene supressor de tumor p53 nas células de ATLL ${ }^{25}$. Nesse estudo, foi demonstrada em uma linhagem celular leucêmica que a perda de função do gene p53 é caracterizada pela diminuição da expressão dos genes p21/CDKN1A e GADD45A, alvos da proteína $\mathrm{p53}$, quando há presença da $\mathrm{HBZ}^{25}$. Ambas as proteínas promovem a parada do ciclo celular e permitem que célula entre em processo de senescência. Dessa forma, acredita-se que a HBZ seja capaz de alterar a expressão dessas proteínas e assim evite que a células entrem em senescência, favorecendo a imortalização das células da ATLL.

\section{Inibição da apoptose}

A HBZ também promove a imortalização celular a partir de mecanismos que impedem a apoptose, como a ativação da cascata mTOR, diminuição de proteínas pró-apoptóticas e aumento dos níveis de $\mathrm{MCL1}^{26,27,28}$. A cascata de sinalização mTOR está associada a processos carcinogênicos e, inclusive, está ativada em células de $\mathrm{ATLL}^{26}$. Essa cascata de sinalização, quando ativada, promove o crescimento celular e a inibição da apoptose ${ }^{26}$. A HBZ interage com a proteína grouth arrest and DNA damage inducible protein 34 (GADD34) e impede a sua atividade supressora na cascata $\mathrm{mTOR}^{26}$. Assim, a HBZ pode contribuir para a ativação dessa cascata e a consequente inibição da apoptose. A HBZ também promove a diminuição das proteínas pró-apoptóticas Bim e FasL, que participam das vias apoptóticas intrínseca e extrínseca, respectivamente, e também induz o aumento da expressão da proteína antiapoptótica MCL1 ${ }^{27,28}$.

Apesar desses artigos constatarem a participação da HBZ no processo de imortalização de células leucêmicas, é importante ressaltar que um estudo feito em 2006 mostrou que o silenciamento da HBZ não impede o processo de imortalização nas células infectadas pelo HTLV$1^{29}$.

Muitos estudos trazem Tax como a proteína responsável pelo processo inicial de transformação celular ${ }^{5,6,18}$, mas, como abordado anteriormente, Tax deixa de ser expressa nas células de pacientes com ATLL enquanto a HBZ continua presente ${ }^{15}$. Dessa maneira, supõe-se que a HBZ talvez não seja essencial no início do processo de imortalização, mas todos esses dados a configuram como uma proteína viral importante na manutenção dessa característica maligna após o efeito inicial de Tax.

\section{Proliferação celular}

A partir de estudos iniciais em murinos há 10 anos atrás, foi observado que a HBZ induz a proliferação e migração celular e, em 2011, foi comprovado que a HBZ consegue promover a formação de tumor em murinos ${ }^{15,30}$. Nos anos conseguintes, esses resultados foram confirmados com estudos em células humanas. Esses estudos mostraram que a HBZ prejudica a via Wnt canônica, promovendo um aumento na sinalização TGF- $\beta$ e na expressão da proteína não-canônica Wnt5a, além de aumentar a expressão da proteína brain-derived neutrophic fator $(\mathrm{BDNF})^{31,32,33}$. Todos esses processos favorecem a proliferação celular.

A proteína HBZ participa também da inibição da produção de IFN- $\beta$, o que consequentemente leva a limitação da produção de IFN- $\alpha^{34}$. Ao evitar a expressão de IFN- $\alpha$ a célula viral consegue evadir seus efeitos antivirais e, assim, viabilizar a sobrevivência celular ${ }^{34}$.

Estudos complementares demonstraram que a HBZ induz a diminuição da expressão de uma proteína que regula o ciclo celular, a ciclina D $1^{19,35}$. Essa proteína participa da indução da fase S durante o ciclo celular e diminuição da sua expressão contribui para a parada do ciclo. Esses resultados são contraditórios aos resultados 
anteriores, já que não é possível ocorrer proliferação monoclonal com a parada do ciclo celular. Porém, apesar desse estudo ter sido feito com células de linhagem leucêmicas, essas células não são específicas de ATLL.

Seria interessante a confirmação desses resultados em amostras de ATLL para avaliar a expressão da ciclina D1 nessa patologia. Sabe-se que Tax apresenta um efeito contrário ao da HBZ e estimula a expressão de ciclina $\mathrm{D} 1^{36}$, mas como no decorrer da infecção os níveis de Tax diminuem, é possível que haja algum outro mecanismo capaz de suprimir esse efeito da HBZ na ciclina D1 e permitir a proliferação monoclonal e o desenvolvimento de ATLL.

\section{A HBZ promove a sua própria expressão}

A célula de ATLL consegue manter a expressão da HBZ de forma continua, porém, o mecanismo preciso da expressão da HBZ até então foi pouco esclarecido ${ }^{29}$. Foi descrito em 2016 que Tax não influencia a transcrição do gene da HBZ em células leucêmicas ${ }^{37}$ e, em 2012, um estudo demonstrou que a HBZ se associa a JunD em outro processo além da expressão da telomerase abordado anteriormente ${ }^{38}$.

No estudo de 2012 foi constatado que a HBZ interage com JunD e a Sp1 e, ao se ligarem a região promotora do gene da $\mathrm{HBZ}$, promovem a transcrição desse gene e expressão da $\mathrm{HBZ}^{38}$. Então, a HBZ além de influenciar expressão de outras proteínas que auxiliam no processo de malignidade das células, também acaba promovendo a sua própria expressão por meio de um feedback positivo, colaborando com a manutenção da sua expressão na célula de ATLL. $H B Z$

Relação entre a carga proviral e a expressão da

Em um estudo epidemiológico do Japão, a carga proviral alta de paciente infectados pelo HTLV-1 foi correlacionada com o desenvolvimento de ATLL, apesar de indivíduos assintomáticos também apresentaram uma carga proviral alta ${ }^{39}$.

Ao investigar a relação entre a HBZ e a carga proviral, dois estudos obtiveram diferentes resultados. Enquanto em um estudo no Irã foi encontrado uma correlação positiva entre a carga proviral e os níveis de RNAm da HBZ, em outro estudo no Japão não houve correlação ${ }^{40,41}$. A partir desses resultados ainda não é possível afirmar a relação entre HBZ e a carga proviral.

\section{A imunogenicidade da HBZ}

Estudos sugerem que pacientes com ATLL possuem imunorreatividade contra a $\mathrm{HBZ}^{41,42}$. No estudo de Enose-Akahata et al (2013), 16,7\% dos indivíduos com ATLL apresentaram anticorpos anti-HBZ, e no estudo de Shiohama et al. (2016) observou-se um resultado semelhante $(12,36 \%)^{41,42}$. Os níveis de anticorpos de HBZ são menores quando comparados com os níveis de outras proteínas virais, como Tax e as proteínas codificadas a partir dos genes gag e env ${ }^{41}$. Então, apesar de alguns indivíduos apresentarem anticorpos contra a HBZ, essa proteína parece apresentar uma baixa imunogenicidade.

Apesar de ter uma provável baixa imunogenicidade, estudos in vitro demonstram que a HBZ é reconhecida por linfócitos T citotóxicos e leva a produção de células imunes específicas. Entretanto, esses linfócitos não foram capazes de provocar lise celular em células de $\mathrm{ATLL}^{43}$. Alguns estudos que buscam tratamentos alternativos para ATLL relatam 0 transplante de células-tronco como um tratamento eficaz ${ }^{13}$ e recentemente foi observado que indivíduos com ATLL, que inicialmente não apresentavam respostas específicas de células $\mathrm{T} \mathrm{CD}^{+}$, passaram a ter essa resposta após o transplante alogênico de célulastronco hematopoéticas (HCT) ${ }^{44}$.

\section{Conclusão}

Diante de todos esses dados fica claro a importância da HBZ no desenvolvimento de ATLL. Contudo, não foi ainda esclarecido o principal motivo pelo qual alguns indivíduos desenvolvem essa patologia enquanto outros permanecem assintomáticos ao longo da vida. Para avaliar como a proteína HBZ influencia no desenvolvimento da ATLL é importante que sejam feitos novos estudos com amostras de pacientes com ATLL comparando com pacientes assintomáticos portadores de HTLV-1.

A maioria dos artigos desta revisão avaliavam somente as células de ATLL e ao comparar as características moleculares das células infectadas em ambos os grupos será possível avaliar melhor como o HTLV-1 leva ao desenvolvimento de ATLL e qual o papel da HBZ nesse processo. Apesar de ainda não estar claro o mecanismo principal pelo qual o indivíduo desenvolve a ATLL e como a HBZ está envolvida, os dados sugerem que essa proteína pode ser um bom alvo terapêutico no controle da ATLL. 


\section{Referências}

1. GALLO, Robert C. The discovery of the first human retrovirus: HTLV-1 and HTLV2. Retrovirology, v. 2, n. 1, p. 17, 2005.

2. GESSAIN, Antoine; CASSAR, Olivier. Epidemiological aspects and world distribution of HTLV-1 infection. Frontiers in microbiology, v. 3, 2012.

3. CARNEIRO-PROIETTI, Anna Bárbara F. et al. Infecção e doença pelos vírus linfotrópicos humanos de células T (HTLV-I/II) no Brasil. Rev Soc Bras Med Trop, v. 35, n. 5, p. 499-508, 2002.

4. KARIMI, Mohammad et al. Role of the HTLV-1 viral factors in the induction of apoptosis. Biomedicine \& Pharmacotherapy, v. 85, p. 334-347, 2017.

5. MATSUOKA, Masao; JEANG, Kuan-Teh. Human T-cell leukaemia virus type 1 (HTLV-1) infectivity and cellular transformation. Nature reviews. Cancer, v. 7, n. 4, p. 270, 2007.

6. GIAM, Chou-Zen; SEMMES, Oliver John. HTLV-1 infection and adult T-cell leukemia/lymphoma-a tale of two proteins: Tax and HBZ. Viruses, v. 8, n. 6, p. 161, 2016.

7. GAUDRAY, Gilles et al. The complementary strand of the human T-cell leukemia virus type 1 RNA genome encodes a bZIP transcription factor that down-regulates viral transcription. Journal of virology, v. 76, n. 24, p. 12813-12822, 2002.

8. SILVA, Fernanda Azevedo et al. Leucemia-linfoma de células T do adulto no Brasil: epidemiologia, tratamento e aspectos controversos. Revista Brasileira de Cancerologia, v. 48, n. 4, p. 585-595, 2002.

9. MESNARD, Jean-Michel et al. Roles of HTLV-1 basic zip factor (HBZ) in viral chronicity and leukemic transformation. Potential new therapeutic approaches to prevent and treat HTLV-1-related diseases. Viruses, v. 7, n. 12, p. 6490-6505, 2015.

10. TAGUCHI, Hirokuni et al. An intensive chemotherapy of adult T-cell leukemia/lymphoma: CHOP followed by etoposide, vindesine, ranimustine, and mitoxantrone with granulocyte colonystimulating factor support. JAIDS Journal of Acquired Immune Deficiency Syndromes, v. 12, n. 2, p. 182-186, 1996.

11. TSUKASAKI, Kunihiro et al. Deoxycoformycin-containing combination chemotherapy for adult T-cell leukemialymphoma: Japan Clinical Oncology Group Study (JCOG9109). International journal of hematology, v. 77, n. 2, p. 164-170, 2003.

12. NASR, Rihab et al. Controversies in targeted therapy of adult $\mathrm{T}$ cell leukemia/lymphoma: ON target or OFF target effects?. Viruses, v. 3, n. 6, p. 750-769, 2011.

13. UTSUNOMIYA, $A$. et al. Improved outcome of adult T cell leukemia/lymphoma with allogeneic hematopoietic stem cell transplantation. Bone marrow transplantation, v. 27, n. 1, p. 15, 2001.

14. EDWARDS, Dustin et al. Orf-I and orf-IIencoded proteins in HTLV-1 infection and persistence. Viruses, v. 3, n. 6, p. 861-885, 2011.

15. SATOU, Yorifumi et al. HTLV-I basic leucine zipper factor gene mRNA supports proliferation of adult $\mathrm{T}$ cell leukemia cells. Proceedings of the National Academy of Sciences of the United States of America, v. 103, n. 3, p. 720-725, 2006.

16. SUGATA, Kenji et al. Protective effect of cytotoxic T lymphocytes targeting HTLV-1 bZIP factor. Blood, v. 126, n. 9, p. 1095-1105, 2015.

17. MOHER, David et al. Preferred reporting items for systematic reviews and meta-analyses: the PRISMA statement. PLoS medicine, v. 6, n. 7, p. e1000097, 2009.

18. LAIRMORE, Michael D.; HAINES, Robyn; ANUPAM, Rajaneesh. Mechanisms of human Tlymphotropic virus type 1 transmission and disease. Current opinion in virology, v. 2, n. 4, p. 474-481, 2012.

19. MA, Yunyun et al. The HTLV-1 HBZ protein inhibits cyclin D1 expression through interacting with the cellular transcription factor CREB. Molecular biology reports, v. 40, n. 10, p. 5967-5975, 2013.

20. MUKAI, Risa; OHSHIMA, Takayuki. HTLV$1 \mathrm{bZIP}$ factor suppresses the centromere protein B (CENP-B)-mediated trimethylation of histone H3K9 through the abrogation of DNA-binding ability of CENP-B. Journal of General Virology, v. 96, n. 1, p. 159-164, 2015.

21. RAVAL, Goutham U. et al. Localization, quantification and interaction with host factors of endogenous HTLV-1 HBZ protein in infected cells and ATL. Retrovirology, v. 12, n. 1, p. 59, 2015.

22. VERNIN, Céline et al. HTLV-1 bZIP factor HBZ promotes cell proliferation and genetic instability by activating OncomiRs. Cancer research, 2014.

23. BOROWIAK, Malgorzata et al. HTLV-1 bZIP factor impedes the menin tumor suppressor and upregulates JunD-mediated transcription of the hTERT gene. Carcinogenesis, v. 34, n. 11, p. 2664-2672, 2013.

24. SHAY, Jerry $W$. et al. Telomerase and cancer. Human molecular genetics, v. 10, n. 7, p. 677-685, 2001. 
25. WRIGHT, Diana G. et al. Human T-cell leukemia virus type-1-encoded protein HBZ represses p53 function by inhibiting the acetyltransferase activity of p300/CBP and HBO1. Oncotarget, v. 7, n. 2, p. 1687, 2016.

26. MUKAI, R.; OHSHIMA, T. HTLV-1 HBZ positively regulates the mTOR signaling pathway via inhibition of GADD34 activity in the cytoplasm. Oncogene, v. 33, n. 18, p. 2317, 2013.

27. MUKAI, Risa; OHSHIMA, Takayuki. Enhanced Stabilization of MCL1 by the Human TCell Leukemia Virus Type 1 bZIP Factor Is Modulated by Blocking the Recruitment of Cullin 1 to the SCF Complex. Molecular and cellular biology, v. 36, n. 24, p. 3075-3085, 2016.

28. TANAKA-NAKANISHI, Azusa et al. HTLV-1 bZIP factor suppresses apoptosis by attenuating the function of FoxO3a and altering its localization. Cancer research, v. 74, n. 1, p. 188200, 2014.

29. ARNOLD, Joshua et al. Enhancement of infectivity and persistence in vivo by $\mathrm{HBZ}$, a natural antisense coded protein of HTLV-1. Blood, v. 107, n. 10, p. 3976-3982, 2006.

30. SATOU, Yorifumi et al. HTLV-1 bZIP factor induces T-cell lymphoma and systemic inflammation in vivo. PLoS pathogens, v. 7, n. 2, p. e1001274, 2011.

31. MA, Guangyong et al. HTLV-1 bZIP factor dysregulates the Wnt pathways to support proliferation and migration of adult T-cell leukemia cells. Oncogene, v. 32, n. 36, p. 42224230, 2013.

32. PANFIL, Amanda R. et al. Functional Comparison of $\mathrm{HBZ}$ and the Related $\mathrm{APH}-2$ Protein Provides Insight into Human T-Cell Leukemia Virus Type 1 Pathogenesis. Journal of virology, v. 90, n. 7, p. 3760-3772, 2016.

33. POLAKOWSKI, Nicholas et al. HBZ stimulates brain-derived neurotrophic factor/TrkB autocrine/paracrine signaling to promote survival of human T-cell leukemia virus type 1-Infected T cells. Journal of virology, v. 88, n. 22, p. 13482-13494, 2014

34. NARULLA, Manraj Singh et al. Positive and negative regulation of type I Interferons by the human $T$ cell leukemia virus antisense protein HBZ. Journal of Virology, v. 91, n. 20, p. e0085317, 2017.

35. MA, Yunyun et al. HTLV-1 basic leucine zipper factor downregulates cyclin D1 expression via interactions with NF-kB. International journal of molecular medicine, v. 39, n. 3, p. 764-770, 2017.

36. KIM, Young-Mi et al. The HTLV-1 tax protein cooperates with phosphorylated CREB, TORC2 and p300 to activate CRE-dependent cyclin D1 transcription. Oncogene, v. 29, n. 14, p. 2142-2152, 2010.

37. LAVERDURE, Sylvain et al. Permissive sense and antisense transcription from the $5^{\prime}$ and $3^{\prime}$ long terminal repeats of human T-cell leukemia virus type 1 . Journal of virology, v. 90, n. 7, p. 3600-3610, 2016.

38. GAZON, Hélène et al. Human T-cell leukemia virus type 1 (HTLV-1) bZIP factor requires cellular transcription factor JunD to upregulate HTLV-1 antisense transcription from the $3^{\prime}$ long terminal repeat. Journal of virology, $v$. 86, n. 17, p. 9070-9078, 2012.

39. IWANAGA, Masako et al. Human T-cell leukemia virus type I (HTLV-1) proviral load and disease progression in asymptomatic HTLV-1 carriers: a nationwide prospective study in Japan. Blood, v. 116, n. 8, p. 1211-1219, 2010.

40. AKBARIN, Mohammad Mehdi et al. Evaluation of the role of TAX, HBZ, and HTLV-1 proviral load on the survival of ATLL patients. Blood research, v. 52, n. 2, p. 106-111, 2017.

41. SHIOHAMA, Yasuo et al. Absolute quantification of HTLV-1 basic leucine zipper factor (HBZ) protein and its plasma antibody in HTLV-1 infected individuals with different clinical status. Retrovirology, v. 13, n. 1, p. 29, 2016.

42. ENOSE-AKAHATA, Yoshimi et al. Humoral immune response to HTLV-1 basic leucine zipper factor (HBZ) in HTLV-1-infected individuals. Retrovirology, v. 10, n. 1, p. 19, 2013. 43. SUEMORI, Koichiro et al. HBZ is an immunogenic protein, but not a target antigen for human T-cell leukemia virus type 1-specific cytotoxic $\mathrm{T}$ lymphocytes. Journal of General Virology, v. 90, n. 8, p. 1806-1811, 2009.

44. NARITA, Tomoko et al. HTLV-1 bZIP Factor-Specific CD4 T Cell Responses in Adult T Cell Leukemia/Lymphoma Patients after Allogeneic Hematopoietic Stem Cell Transplantation. The Journal of Immunology, v. 192, n. 3, p. 940-947, 2014.

\section{Endereço para Correspondência}

Escola Bahiana de Medicina e Saúde Pública Av. Dom João VI, 275 - Brotas, Salvador - BA

CEP.: 40285-000

e-mail: carolinegarcez@outlook.com

Recebido em 04/04/2018

Aprovado em 12/06/2018

Publicado em 20/12/2018 